\title{
Sialólito no ducto da glândula mandibular em cão
}

\author{
Sialolith inside mandibular gland duct in dog \\ Víviam Nunes Pignone', Cláudia Stringhini Faraco², Paulo Barros de Albuquerque ${ }^{3}$, \\ Guilhermo Recla ${ }^{3}$, Giordano Gianotti ${ }^{1} \&$ Emerson Antonio Contesini ${ }^{4}$
}

\begin{abstract}
RESUMO
A sialocele consiste no acúmulo de saliva nos tecidos moles, a qual pode ser desencadeada por ruptura dos ductos salivares. Entre as etiologias, destaca-se a presença de cálculo no interior do ducto ou da glândula salivar, denominada sialolitíase, clinicamente caracterizada por edema e ausência de dor. A deposição de sais minerais no interior das glândulas associada ao acúmulo de muco, bactérias e células epiteliais descamadas podem originar o sialólito, bem como o pH alcalino, que fica em torno de oito na espécie canina. O relato tem como objetivo descrever um caso de sialocele na glândula mandibular causada por sialólito em um cão da raça Pastor Alemão atendido no Hospital de Clínicas Veterinárias (HCV) da Universidade Federal do Rio Grande do Sul (UFRGS). O diagnóstico baseou-se em anamnese, exame físico e exames complementares, como citologia do aspirado, e, como tratamento, indicou-se remoção da cadeia e do ducto glandular mandibular e sublingual afetado, aliada à retirada do sialólito. No caso relatado, a sialoadenectomia das glândulas afetadas juntamente com a remoção do sialólito presente no ducto da glândula mandibular foram eficazes no tratamento sem recidiva.
\end{abstract}

Descritores: sialólito, sialocele, cão, glândula mandibular.

\begin{abstract}
Sialocele is an accumulation of saliva in the soft tissues which can be triggered by collapse of the salivary ducts. One of the causes is the presence of stone inside the duct or in salivary gland - sialolithiasis - characterized by intermittent swelling, edema and no pain. The sialolith can be caused by minerals deposition in the glands associated with the accumulation of mucus, peel epithelial cells, bacteria and the alkaline $\mathrm{pH}$, which is around eight in dogs. This report refers to a male German Shepherd Dog with sialocele in the mandibular gland caused by sialolith treated at the Hospital de Clínicas Veterinárias of the Universidade Federal do Rio Grande do Sul, RS, Brazil. The diagnosis was based on history, physical examination and diagnostic procedures, like a cytology. The treatment was removal of the chain and the duct of mandibular and sublingual gland, that was affected by sialolith. In this case, the mandibular and sublingual gland excision with removal sialolith present in the duct were effective in the treatment without recurrence.
\end{abstract}

Keywords: sialolith, sialocele, dog, mandibular gland. 


\section{INTRODUÇÃO}

As glândulas salivares são divididas anatomicamente em maiores e menores, sendo as primeiras representadas pela parótida, zigomática, mandibular e sublingual e as segundas pela lingual, labial, bucal e palatina $[4,5,12,15]$.

As sialoceles, também denominadas mucoceles ou rânulas, são originadas por rupturas dos ductos salivares, seja por traumatismo, presença de cálculos ou causas desconhecidas. Quando a glândula mandibular é afetada, clinicamente se constata um aumento flutuante e indolor na parte ventral do pescoço $[2,4,11,12,15]$. Entre as raças mais predispostas, destacam-se o Poodle, o Pastor Alemão, o Yorkshire e o Dachshund.

Os sialólitos são estruturas mineralizadas que podem se formar dentro do tecido glandular ou em seus ductos $[1,2,5,9,15]$, sendo rara em cães $[3,7]$. Existem evidências de que estes se formam devido à deposição de sais minerais no interior das glândulas associado com muco, bactérias e células epiteliais descamadas [1,9], além do $\mathrm{pH}$ alcalino da saliva nesta espécie também possa predispor a esta doença [15].

$\mathrm{O}$ exame radiográfico pode ser indicado em casos de sialolitíase, corpo estranho ou neoplasia $[6,7,15]$. Entretanto, a sialografia, apesar da sua dificuldade de execução, tem como vantagem determinar qual lado e qual glândula foi afetado injetando 0,5 a $1,5 \mathrm{~mL}$ de contraste radiopaco através de um cateter pequeno introduzido no orifício do ducto $[6,15]$.

O tratamento de eleição neste caso consiste na remoção da cadeia e do ducto das glândulas mandibular e sublingual afetado aliada a remoção do sialólito [4-6,13-15].

Este trabalho descreve um caso de um Pastor Alemão atendido no HCV-UFRGS que apresentava sialocele tendo como causa um sialólito na glândula mandibular.

\section{RELATO DE CASO}

Foi atendido no HCV-UFRGS um canino da raça Pastor Alemão, com sete anos de idade, macho, pesando $35 \mathrm{~kg}$, o qual apresentava um aumento de volume na região mandibular ventral, de consistência macia de aproximadamente $10 \mathrm{~cm}$ de diâmetro. Segundo o proprietário, havia uma evolução de um mês e não relatou trauma. Procedeu-se a punção dessa massa para análise citológica que evidenciou conteúdo salivar.
Baseando-se na anamnese, no exame físico e complementar, suspeitou-se de sialocele da glândula mandibular, ficando indicado como tratamento a realização da sialoadenectomia. Como medida pré-operatória, preconizouse a realização de exames pré-cirúrgicos básicos necessários, os quais não evidenciaram qualquer alteração digna de nota, encaminhando o paciente para a cirurgia.

Como medicação pré-anestésica, foi administrado cloridrato de meperidina ${ }^{1}\left(3 \mathrm{mg} \cdot \mathrm{kg}^{-1} \mathrm{IM}\right)$ associado com tiletamina e zolazepam ${ }^{2}$ (3mg.kg $\left.{ }^{-1} \mathrm{IM}\right)$, sendo realizada a venóclise, para manter uma via de acesso infundindo solução de ringer lactato e tricotomia da região após 10 minutos da aplicação. A indução deu-se com propofol ${ }^{3}$ (5mg.kg-1 IV) e manutenção com iso-flurano ${ }^{4}$ ao efeito.

Incisou-se a pele na região do aumento de volume ventral ao pescoço divulsionando e tentando identificar qual glândula e lado estava sendo afetada (Figura 1A). Após dissecar a glândula mandibular e sublingual direita, observou-se a presença de uma estrutura mineralizada semelhante a um sialólito no ducto da glândula mandibular (Figura 1B). A sialoadenectomia dessas glândulas foi realizada, fazendo posteriormente a lavagem com solução de $\mathrm{NaCl} 0,9 \%$, redução do espaço morto e síntese de pele com fio inabsorvível sintético náilon 2-0 e colocação de dreno de penrose (Figura 1F).

Finalizado o procedimento, inspecionaram-se as glândulas que foram removidas e, por meio de dissecação, confirmando a presença de sialólito de aproximadamente $2 \mathrm{~cm}$ de diâmetro e outros menores (Figuras 1C-E).

Este cão recebeu no pós-operatório imediato cloridrato de tramadol ${ }^{5}\left(2 \mathrm{mg} \cdot \mathrm{kg}^{-1} \mathrm{IM}\right)$ e cetoprofeno ${ }^{6}$ $\left(2 \mathrm{mg} \cdot \mathrm{kg}^{-1} \mathrm{SC}\right)$. Foi prescrita a administração de enrofloxacina $^{7}$ (5mg.kg ${ }^{-1}$ BID 10 dias), meloxicam ${ }^{8}$ (0,2mg. $\mathrm{kg}^{-1}$ SID 10 dias) e colocação de colar elisabetano. Decorrido dois dias da cirurgia, o animal retornou ao HCVUFRGS, pois o paciente havia removido o dreno pelo não uso do colar elisabetano e indicou-se limpeza da ferida diariamente com solução fisiológica e pomada a base de neomicina até completa cicatrização. Após 19 dias, o paciente foi reavaliados e retirados os pontos. Constatando-se que os mesmos estavam em bom estado, recebeu alta.

\section{DISCUSSÃO}

A sialocele é uma doença que atinge mais cães do que gatos, sendo que o Pastor Alemão é uma das raças predispostas a desenvolvê-la, tendo como fator 


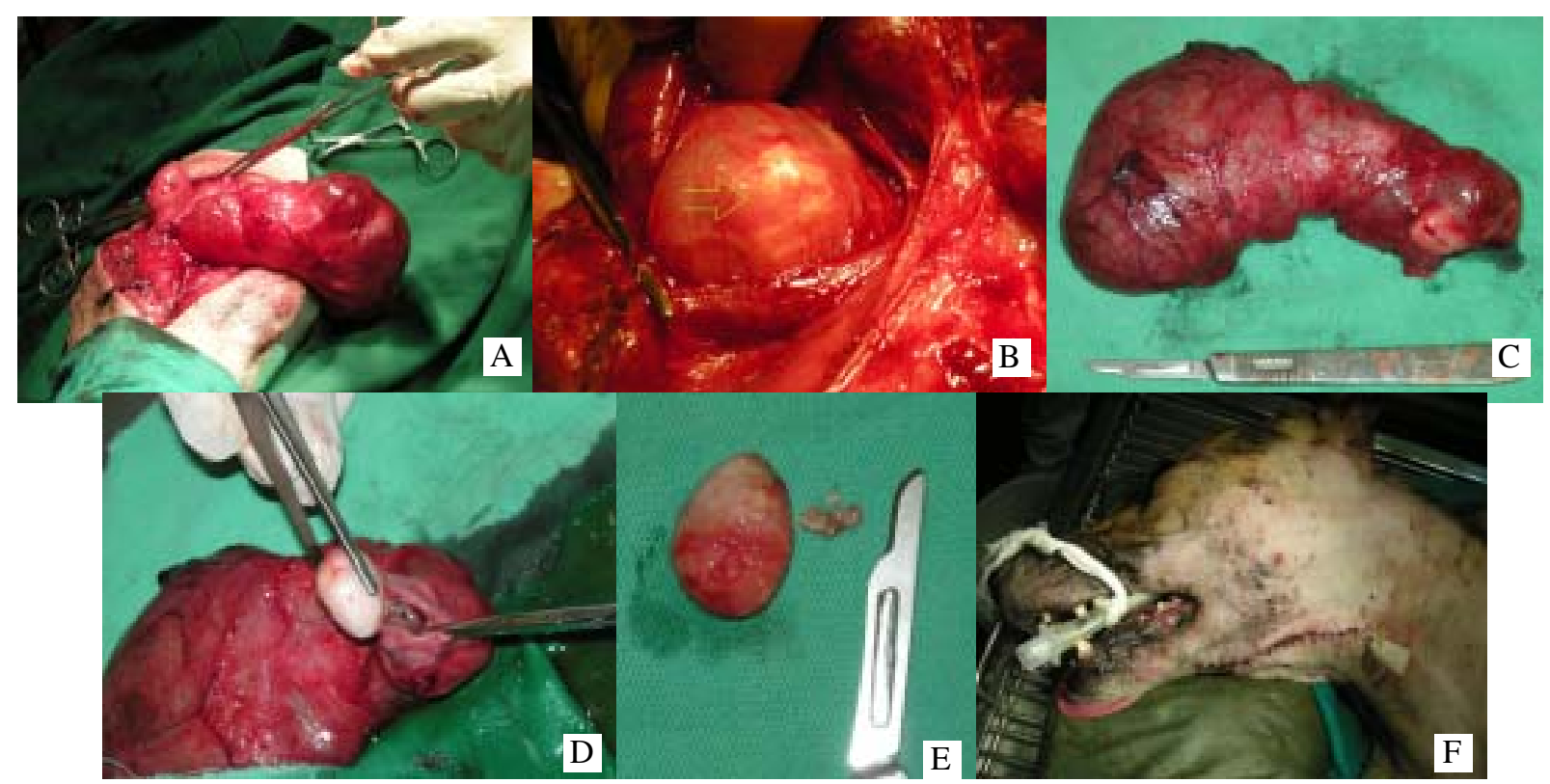

Figura 1. (A) Glândula salivar mandibular e sublingual direita após dissecação preservando a cápsula; (B) presença do sialólito no ducto da glândula mandibular (seta verde); (C) glândulas removidas íntegras; (D) retirada do sialólito de dentro do ducto; (E) sialólito de aproximadamente $2 \mathrm{~cm}$ e outros pequenos; (F) aspecto cirúrgico final do paciente após colocação do dreno de penrose.

desencadeante a presença de sialólito comprovando o caso relatado [4-6,15]. Os sinais clínicos apresentados pelo paciente consistiam no aumento de volume na região cervical ventral indolor à palpação $[2,4,5,9,11$, 12,14,15], porém não era possível afirmar o lado afetado em função do tamanho da massa, sendo descoberto somente no transoperatório.

Embora em casos de sialolitíase seja indicado exame radiográfico, este não foi realizado no paciente impossibilitando identificar o lado afetado, assim como a presença do cálculo. Em humanos, 58 a 96\% dos casos de sialolitíase, com a radiografia simples, é diagnosticada, apesar de a radiopacidade variar de acordo com a composição mineral deste $[1,7]$. $\mathrm{O}$ uso de raio $\mathrm{X}$ contrastado, denominado sialografia, pode ser indicado para diagnosticar ou determinar qual glândula está envolvida [5-7], todavia esse exame é difícil de realizar e, segundo alguns autores, é desnecessário [6].

$\mathrm{O}$ aumento de volume na região ventral do pescoço pode caracterizar diversas etiologias como sialocele, neoplasia, abscesso, sialodenite, hematoma ou cisto [6], ficando indicado realizar punção para análise citológica para fazer o diagnóstico [5,6], conforme realizado no paciente. A colheita do aspirado deve ser feita de maneira asséptica, sendo que, em casos de sialocele, o líquido pode apresentar coloração de amarelo-palha a avermelhada, de consistência viscosa, e microscopicamente observa-se a presença de saliva, e poucas células sanguíneas e inflamatórias, assim como foi encontrado no caso relatado [5,6,8,14].

A maioria dos autores indica como tratamento a sialoadenectomia da(s) glândula(s) afetadas [2$6,10,11,15]$, embora também possa optar pela realização de uma fístula para drenagem da saliva, denominada marsupialização, quando a sialocele for na glândula sublingual [5,6]. Para remoção da glândula salivar mandibular, indica-se posicionar o paciente em decúbito lateral com o lado acometido para cima, entretanto, devido à dificuldade de identificar o lado afetado, optou-se por deixá-lo em decúbito dorsal. Durante a divulsão dos tecidos no transoperatório, foi possível observar que as glândulas envolvidas eram a mandibular e a sublingual direita, assim como a presença de sialólito dentro do ducto da glândula mandibular.

Para obter maior precisão ao realizar a abordagem, recomenda-se prender a glândula entre os dedos ao realizar a incisão sobre esta [5], principalmente neste caso, em que não se sabiam quais glândulas salivares nem o lado que estava envolvido, evitando lesar outras estruturas e a vascularização local como as veias linguofacial, maxilar e jugular [4-6,15]

Durante o transoperatório, foi identificado o sialólito (Figura 1B), que, ao término da cirurgia, foi encontrada dentro do ducto da glândula mandibular, confirmando ser o agente desencadeante da sialocele. 
Os achados bibliográficos afirmam que o sialólito pode ser composto por fosfato de cálcio ou carbonato $[1,6]$.

Preconiza-se que, ao fazer a sialoadenectomia, a cápsula da glândula seja preservada, evitando extravasamento de saliva, conforme foi realizado [4-6,15]. A utilização de dreno de penrose é recomendada em casos de sialoadenectomia das glândulas mandibular e sublingual, prevenindo formação de seromas, devendo permanecer de 24 a 72 horas no pós-operatório [5,6, $11,15]$. Neste caso, foi colocado o dreno de penrose no paciente, o qual permaneceu durante $48 \mathrm{~h}$, sendo removido por ele, porém não prejudicou o sucesso da terapia instituída.
Decorridos nove meses do tratamento, não foi observado qualquer sinal clínico de recidiva, podendo se concluir que o tratamento foi eficaz.

\section{NOTAS INFORMATIVAS}

${ }^{1}$ Dolosal ${ }^{\circledR}$ - Cristália, rod. Itapira, km 14, Itapira, SP, Brasil. ${ }^{2} Z^{2}{ }^{2}$ tetil ${ }^{\circledR}$ - Virbac do Brasil, São Paulo, SP, Brasil.

${ }^{3}$ Propovan ${ }^{\circledR}$ - Cristália, rod. Itapira, km 14, Itapira, SP, Brasil. ${ }^{4}$ Forane $^{\circledR}$ - Abbott, Rua Nova York, 245, São Paulo, SP, Brasil. ${ }^{5} \mathrm{Tramal}^{\circledR}$ - Cristália, rod. Itapira, km 14, Itapira, SP, Brasil. ${ }^{6}$ Ketofen $^{\circledR}$ - Rhodia Mérieux, Fazendo São Francisco, Paulínea, SP, Brasil.

${ }^{7}$ Baytril $^{\oplus}$ - Bayer, Domingos Jorge, 1000, São Paulo, SP, Brasil.

${ }^{8}$ Meloxivet $^{\circledR}$ - Duprat, Rua Almirante Oliveira Pinto, 267, Rio de Janeiro, RJ, Brasil.

\section{REFERÊNCIAS}

1 Alcure M.L., Vargas P.A., Jorge Júnior J., Hipólito Júnior O. \& Lopes M.A. 2005. Clinical and histopatological finding of sialoliths. Brazilian Journal of Oral Science. 15: 899-903.

2 Bravo P. S., Montes C.L., Sanchez I. M. \& Ortiz M.G. 2006. Sialolitiasis da glândula sublingual. Presentación de um caso clínico y revisión de la literatura. Revista de la Associación Dental Mexicana. 63: 32-36.

3 Dunning D. 2007. Língua, Lábios, Bochechas, Faringe e Glândulas Salivares. In: Slatter D. (Ed). Manual de Cirurgia de Pequenos Animais. 3.ed. Barueri: Manole, v.1., pp.558-560.

4 Emily P. \& Harvey C. 1993. Small Animal Dentistry. St. Louis: Mosby, pp. 413.

5 Gioso M.A. 2007. Glândulas Salivares. In: Odontologia para o Clínico de Pequenos Animais. 2.ed. São Paulo: Manole, pp.109-112.

6 Hedlund C.S. \& Fossum T.W. 2007. Surgery of the Oral Cavity and Oropharynx. In: Fossum T.W. (Ed). Small Animal Surgery. 3rd edn. Missouri: Mosby Elsevier, pp.339-371.

7 Kealy J.K. \& Mcallister H. 2005. O Crânio e a Coluna Vertebral. Radiologia e Ultra-sonografia do Cão e do Gato. 3.ed. Barueri: Manole, pp.368-371.

8 Landgraf H., Assis A.F., Kluppel L.E., Oliveira C.F. \& Gabrielli M.A.C. 2006. Extenso sialólito no ducto da glândula submandibular: relato de caso. Revista de Cirurgia e Traumatologia buco-maxilo-facial. 6: 29-34.

9 Matsumoto M.A., Ribeiro Junior P.D., Nary Filho H. \& Silva A.A. 2005. Sialólito Gigante em Ducto Submandibular. Revista Brasileira de Patologia Oral. 4: 182-184.

10 Mulkey C. \& Knecht C.D. 1971. Parotid Salivary cyst and calculus in a dog. Journal of the American Veterinary Medicinal Association. 159: 1774.

11 Roza M.R. 2004. Cirurgia Dentária e da Cavidade Oral. In: Odontologia em Pequenos Animais. Rio de Janeiro: L.F. livros, pp.167-190.

12 San Roman F., Orozco A.W. \& Muñiz I.T. 1999. Anatomia, Estrutura e Nomenclatura Dental. Atlas de Odontologia de Pequenos Animais. São Paulo: Manole, pp.17-38.

13 Torroni A.A., Mustazza M.C., Bartoli D.D. \& Iannetti G.G. 2007. Transcervical Submandibular Sialoadenectomy. Journal of Craniofacial Surgery. 18: 613-21.

14 Trumpatori B.J., Geissler K. \& Mathews K.G. 2007. Parotid duct sialolithiasis in a dog. Journal of the American Animal Hospital Association. 43: 43-51.

15 Wiggs R. \& Lobprise H. 1997. Veterinary Dentistry - Principles e Practice. Philadelphia: Lippincott - Raven, p.748. 